\title{
Limited hydrolysis of polysialic acid by human neuraminidase enzymes
}

Carmanah D. Hunter and Christopher W. Cairo*

Department of Chemistry, University of Alberta, Edmonton Alberta, T6G 2G2, Canada

*To whom correspondence should be addressed. Tel.: 780492 0377; fax: 780492 8231; e-mail: ccairo@ualberta.ca 


\section{ABSTRACT}

Regulation of sialic acids by human neuraminidase (hNEU) enzymes is important to many biological processes. Defining hNEU substrate tolerance can help to elucidate the roles of these enzymes in regulating sialosides in human health and disease. Polysialic acid (polySia) is a polyanion of $\alpha(2 \rightarrow 8)$ linked sialic acids with roles in nervous, reproductive, and immune systems and is dysregulated in some malignancies and mental disorders. The unique chemical properties of this polymer, which include an enhanced susceptibility to acid-catalyzed hydrolysis, have hampered its study. Herein we describe the first systematic study of hNEU isoenzyme activity towards polysialic acid in vitro. The experimental design allowed us to study the impact of several factors that may influence polysialic acid degradation including $\mathrm{pH}$, polymer size, and the relative ionic strength of the surrounding media. We report that short chains of polysialic acid (degree of polymerization, DP 3-8) were substrates of NEU3 and NEU4 at acidic pH, but not at neutral pH. No hNEU-catalyzed hydrolysis of longer polymers (DP 10-20) was detected. These findings suggest a neuraminidase-independent mechanism for polysialic acid turnover such as internalization and degradation in endosomes and lysosomes. 


\section{INTRODUCTION}

Hydrolysis of the glycosidic bonds of sialic acid by neuraminidase (also known as sialidase) enzymes modulates cell signaling by removing neuraminic acid (sialic acid) epitopes or by revealing epitopes masked by this residue. The regulation of neuraminic acid by enzymes plays important roles in many biological processes including cell-cell interaction, host-pathogen interactions, and tumor malignancy. ${ }^{1,2}$ To date, four human neuraminidase (hNEU) isoenzymes have been identified which differ in subcellular localization and substrate tolerance. ${ }^{1}$ Small molecule inhibitors ${ }^{3}$ and unnatural neuraminic acid substrates ${ }^{4-6}$ have been valuable tools to further understanding of $\mathrm{hNEU}$ structure and substrate tolerance; however, many natural sialosides are unstable and difficult to isolate which has impeded their study. ${ }^{7,8}$

Diversity in sialic acid presentation is generated at three levels: modification of the monosaccharide (e.g. hydroxyl groups or the $C-5$ amido group), the glycosidic bond (typically $\alpha(2 \rightarrow 3,6$, or 8$)$ ), or the reducing end glycans or aglycone. ${ }^{9}$ Previous work has indicated that all three levels of sialic acid diversity influence hNEU catalyzed hydrolysis, both independently and in synergy., 10-12 These results suggest that in order to understand the interaction of uncommon sialic acids with hNEU it is important to study a range of well-defined substrates.

Polymers of $\alpha(2 \rightarrow 8)$ linked sialic acids (polysialic acid, polySia) are sialylglycoconjugates with unique chemical properties. In human systems polySia has been predominantly studied on NCAM, which can account for as much as $80 \%$ of total polySia, ${ }^{13}$ and where the degree of polymerization (DP) can be up to 90 residues. $^{14}$ Polysialic acid has also been found on synCAM, ${ }^{15}$ neuropilin, ${ }^{16}$ E-selectin, ${ }^{17}$ CD36 in 
human milk, ${ }^{18}$ the $\alpha$-subunit of the voltage-sensitive sodium channel, ${ }^{19}$ and on polysialyltransferases ST8SiaII and ST8SiaIV. ${ }^{20}$ The biological role of polySia is often ascribed to that of a non-specific anti-adhesive or pro-migratory molecule for cells. ${ }^{21,} 22$ In recent years specific binders to polySia have emerged, including neurotrophins like BDNF, ${ }^{23}$ and FGF $2 .{ }^{24}$ Polysialyltransferase activity regulates the activation of CD4+ Tcells $^{25}$ and knock-out of the polysialyltransferase ST8SiaIV resulted in T-cell defects in mice. ${ }^{26}$ PolySia has been found on other immune cells, ${ }^{16,26,27}$ and is more abundant in the serum of males compared to females, suggestiong the possibility that polySia may contribute to sex differences in immune response. ${ }^{28}$ In some cancers dysregulation of polySia promoted malignancy. ${ }^{29-32}$ Polysialic acid regulates neuronal development and plasticity, ${ }^{33}$ and it has recently been gaining traction as a molecule associated with mental disorders ${ }^{34}$ In the brain polySia levels are increased in bipolar disorder, ${ }^{35}$ but decreased in depression, ${ }^{35}$ schizophrenia, ${ }^{36}$ and acute stress. ${ }^{37}$ Understanding the mechanisms of polySia regulation are critical to elucidation of specific roles for this polyanion in human health and disease.

The unique chemical properties of polySia can largely be attributed to the $\mathrm{C} 1$ carboxylate of sialic acid monomers, making the polymer polyanionic at neutral $\mathrm{pH}$. As a result, polySia is known to have a large hydration volume, ${ }^{38}$ which is influenced by charge screening from ions in the surrounding solution. ${ }^{39}$ The pKa of polySia increases with increasing chain length (Figure S1A), and can range from 2.9-5.5. ${ }^{40}$ The carboxylate groups influence stability of the polymer. An intramolecular self-cleavage mechanism, where a protonated $\mathrm{C} 1$ carboxylic acid acts as a proton donor to the glycosidic $\mathrm{O} 2$, is proposed to explain the susceptibility of polySia to acid-catalyzed 
hydrolysis (Figure S1B) ${ }^{41}$ Notably, polysialic acid is known to hydrolyze even under the mild acidic conditions present in cellular compartments such as endosomes and lysosomes. ${ }^{41}$ Protonation of the $\mathrm{C} 1$ carboxylate can result in formation of lactones between the $\mathrm{C} 1$ and $\mathrm{C} 9$ of the neighboring reducing-end residue. ${ }^{42,}{ }^{43}$ The $\mathrm{C} 1$ carboxylate contributes to the formation of polySia tertiary structure - which is generally thought to be an extended helix. ${ }^{44}$

The chemical properties of polySia make it challenging to study. Polysialic acid studies in vitro have relied heavily on reducing-end reactivity in a thiobarbituric acid assay, ${ }^{45,46}$ or 1,2-phenylenediamines for analysis of chain length using anion-exchange HPLC. ${ }^{46}$ Both reducing-end chemistries require acidic conditions which would degrade the polymer, making accurate analysis of polySia difficult. ${ }^{47,48}$ In cellulo analysis of polySia has relied almost exclusively on anti-polySia antibodies that recognize epitopes that are not always well defined. ${ }^{48}$ A polySia-specific probe has been developed from an inactive mutant of endosialidase that binds, but does not cleave, polySia, ${ }^{49-51}$ however, it has not yet been widely adopted.

Literature reports of hNEU hydrolysis of polySia have been limited and sometimes contradictory. In vitro and in cellulo studies have reported that NEU4 is the only isoenzyme to cleave polySia, ${ }^{46,52}$ while a separate report suggests only NEU1 regulates polySia. ${ }^{13}$ An in vivo study in rats detected increased NEU1 in brain tissues upon LPS stimulation corresponded to a decrease in polySia. ${ }^{53}$ Knockdown of NEU1 led to an increase in polySia on hippocampal granule cells. ${ }^{54}$ Although these results implicate NEU1 in the regulation of polySia, they do not provide direct evidence for NEU1 hydrolysis of polySia. We considered that a systematic study of polySia hydrolysis by 
hNEU isoenzymes would provide important insight into this problem. Here, we describe in vitro hydrolysis assays of polySia of varying lengths with each of the hNEU isoenzymes. We find that only NEU3 and NEU4 show significant amounts of hydrolysis for polySia under acidic conditions; and that the hNEU isoenzymes do not act on polySia substrates of high DP (10-20).

\section{RESULTS AND DISCUSSION}

Preparation of substrates for degradation assays.

To study polysialic acid degradation we required defined polySia substrates and a reliable method to detect polySia chain length. Reducing-end labeling of sialic acids with 1,2-phenylenediamines followed by HPLC separation is a well-established method for the analysis of sialic acid monosaccharides ${ }^{55,56}$ and polymers. ${ }^{57}$ Sialic acid labeling with 1,2-phenylenediamines requires acidic conditions which in turn promote the intramolecular self-cleavage of polySia. ${ }^{41}$ The labeling reaction has been optimized to minimize, but not completely eliminate, polySia hydrolysis. ${ }^{47,}{ }^{57}$ Further, under acidic conditions polySia of higher DP hydrolyzed faster than that of lower DP, so background hydrolysis from 1,2-phenyldiamine derivatization may be inconsistent across samples. ${ }^{4 l}$, ${ }^{47}$ The drawbacks to determining polySia chain length through labeling with 1,2phenyldiamines can be circumvented by labeling the polySia substrates prior to submission to test conditions. This early labeling not only eliminated background hydrolysis due to labeling from the polySia degradation assay, but also allowed us to separate and isolate pools of polysialic acid of known DP using preparative HPLC to provide defined substrates. ${ }^{47}$ 
The most common diamine used for sialic acid labeling is 1,2-diamino-4,5methylenedioxyenzene dihydrochloride (DMB) which enables fluorescent detection. However, DMB is unstable to both light and oxygen while being relatively expensive. ${ }^{58}$ A more stable and inexpensive alternative,${ }^{59} o$-phenylenediamine (OPD, 1) (Scheme 1), provided sufficient sensitivity for our purposes. Starting from commercially available and inexpensive colominic acid (average DP $\approx 100$ ), shorter fragments of labeled polySia were produced during reducing-end labeling with OPD over 2 hours at $50{ }^{\circ} \mathrm{C}$ to promote hydrolysis to smaller chain lengths (Scheme 1) ${ }^{57}$ After labeling, anion exchange chromatography with preparative HPLC was used to isolate polymers of defined length. For our degradation assays we generated pools of short chain (DP 3-8) and long chain (DP 10-20) sialic acids, which we henceforth refer to as oligo- and poly-sialic acid, respectively. ${ }^{48}$ These lengths were selected based on conformational studies that suggested polysialic acid adopts extended helical structures where one helical turn is 8-9 sialic acid residues. ${ }^{44,60,61}$ This model indicates that oligoSia $(\mathrm{DP}<8)$ may have a different tertiary structure relative to longer chain polySia (DP 10+), which we reasoned could influence its availability for hNEU-catalyzed hydrolysis.

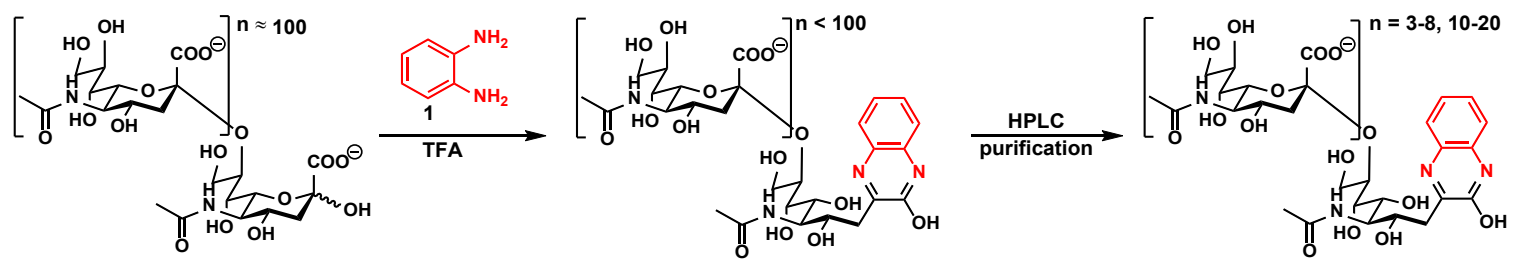

Scheme 1: Preparation of sialic acid polymers for degradation assays 

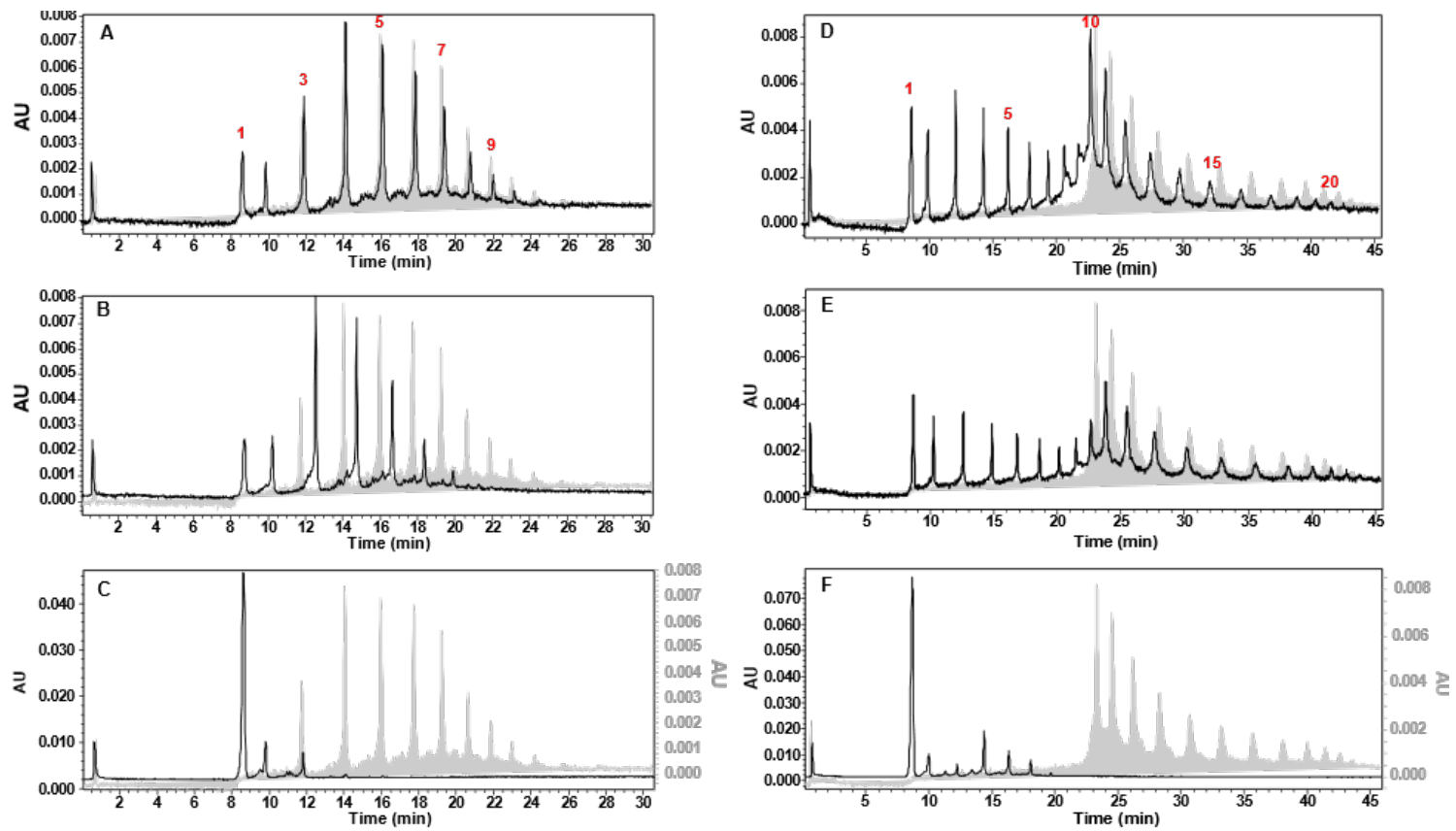

Figure 1: Representative runs of oligosia (A-C) and polysia (D-F) degradation assays. Samples were measured after $5 \mathrm{hrs}$ at $37^{\circ} \mathrm{C}$ where the grey chromatogram indicates time $=0$, and the black chromatogram indicates treatment with $\mathrm{A}, \mathrm{D}) \mathrm{pH} 4.5$ control $\mathrm{B}, \mathrm{E}) 1$ mU NEU3 C, F) $65 \mu \mathrm{g} / \mathrm{mL}$ Endo-N.

\section{Degradation assays.}

To study the degradation of oligo- and polySia, we implemented an endpoint assay where the labeled substrates were incubated with neuraminidase for $5 \mathrm{hrs}$ at $37^{\circ} \mathrm{C}$ before quenching. The samples were analyzed by HPLC using anion exchange chromatography (DNAPac PA-100) to separate polymers of different DP. For analysis, we calculated a weighted average of the peak areas from the raw data (Figure 1) to produce an average DP. Because polymers of sialic acid undergo intramolecular self-cleavage at the $\mathrm{pH}$ optimum of hNEU enzymes ( $\mathrm{pH} 4.5$ for NEU1, NEU3, and NEU4 and 5.5 for NEU2); enzyme-free $\mathrm{pH}$ controls were implemented in addition to a time $=0$ control (Figure 2). The enzyme-free controls used hNEU storage buffer to ensure consistency in $\mathrm{pH}$ and salt 
concentration. Pooled oligoSia (DP 3-8) and polySia (DP 10-20) were stable at pH 7 over the $5 \mathrm{~h}$ experiment, in agreement with previous results, ${ }^{62}$ and only underwent minor hydrolysis at $\mathrm{pH} 5.5$. At $\mathrm{pH} 4.5$ oligoSia had a decrease in average DP of $0.82 \pm 0.03$ over $5 \mathrm{~h}$ (a decrease in molecular weight of $50.7 \mathrm{~g} \mathrm{~mol}^{-1} \mathrm{hr}^{-1}$ ) (Figure 1A), and hydrolysis occurred more rapidly for polySia (Figure 1D, Figure 2) (decrease in DP of $4.15 \pm 0.1$, $247.6 \mathrm{~g} \mathrm{~mol}^{-1} \mathrm{hr}^{-1}$ ), consistent with previous reports. ${ }^{41,47}$ Taken together, these data support the postulated intramolecular self-cleavage (Figure S1). ${ }^{41}$

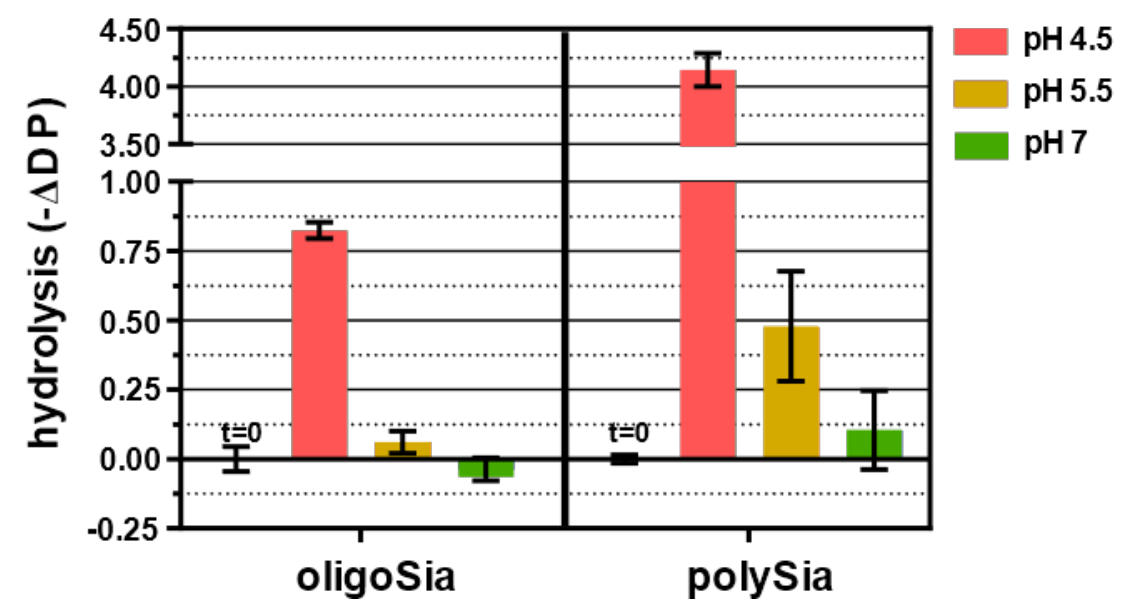

Figure 2: Enzyme-free hydrolysis of oligosia and polysia over 5 hours at $\mathrm{pH} 4.5,5.5$ and 7. Hydrolysis is presented as $-\Delta \mathrm{DP}$ (over $5 \mathrm{hrs}$ ), the change in the average degree of polymerization of the sample normalized to time $=0$ (at left).

Bearing in mind that $\mathrm{pH}$ has a strong influence on enzyme-independent hydrolysis of oligoSia and polySia, we tested oligoSia degradation by neuraminidases both at the enzyme optimum and at $\mathrm{pH}$ 7. Endoneuraminidase-N (Endo-N, from E. coli K1 bacteriophage) was used as a positive control for endosialidase activity. EndoN treatment 
$(65 \mu \mathrm{g} / \mathrm{mL})^{63}$ of oligoSia converted most of the sample to monosaccharide (Figure 1C) at both $\mathrm{pH} 4.5$ and $\mathrm{pH} 7$ (Figure 3A), confirming that the reducing-end labeling conditions did not block oligoSia cleavage. We were surprised to observe that neuraminidase from A. ureafaciens (siaAU), reported to be a relatively indiscriminate $\mathrm{NEU},{ }^{45,64}$ did not show increased hydrolysis of oligoSia or polySia when compared to $\mathrm{pH}$ controls (Figure 3B).

The hNEU isoenzymes exhibited $\mathrm{pH}$-dependent activity towards oligoSia. The enzyme activity for all neuraminidase enzymes was normalized to $0.5-1 \mathrm{mU}$ for the indicated $\mathrm{pH}$. At $\mathrm{pH} 4.5$, NEU3 hydrolyzed oligoSia fastest with a decrease in average DP of $2.00 \pm 0.04$ compared to $0.82 \pm 0.03$ for the $\mathrm{pH} 4.5$ control (Figure 3E). The NEU4 isoenzyme had significant activity on oligoSia (decrease in DP of $1.53 \pm 0.01$, Figure 3F). At its optimum pH, NEU2 did not show detectable hydrolysis of oligoSia relative to the control (Figure 3D), nor did it have activity at more acidic $\mathrm{pH}$ (4.5, data not shown). These results agree with reports that NEU2 has a strong preference for $\alpha(2 \rightarrow 3)$ over $\alpha(2 \rightarrow 6)$ or $\alpha(2 \rightarrow 8)$ linked sialic acids and that it does not to cleave colominic acid. ${ }^{65}$ Previous studies suggested that the NEU2 active site interactions with the glycerol chain are constrained, limiting its substrate tolerance. ${ }^{11,66,67}$ We observed moderate, but not significant, enzyme-catalyzed hydrolysis of oligoSia by NEU1 at $\mathrm{pH}$ 4.5 (Figure 3C). Our NEU1 enzyme preparation was not active at $\mathrm{pH} 7$, preventing measurement under this condition. In general, hNEU isoenzymes showed activity at acidic enzyme optimum $\mathrm{pH}$ (excepting NEU2); however, none of the hNEU cleaved oligoSia at $\mathrm{pH}$ 7. This observation suggests that oligoSia may only be degraded by hNEU in acidic compartments in vivo. 
A) EndoN

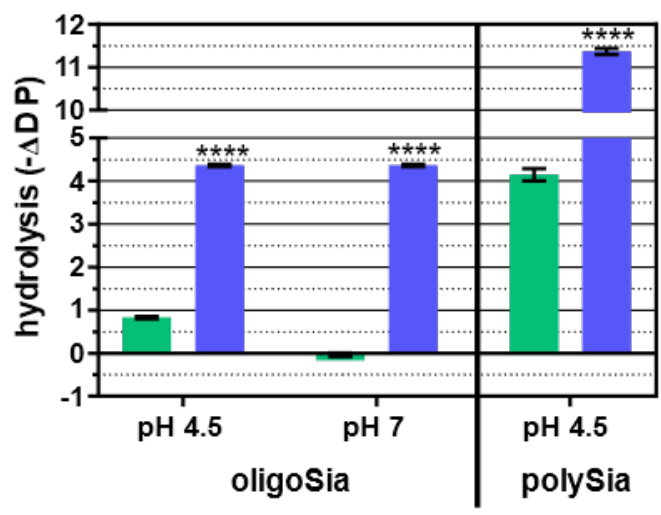

C) NEU1

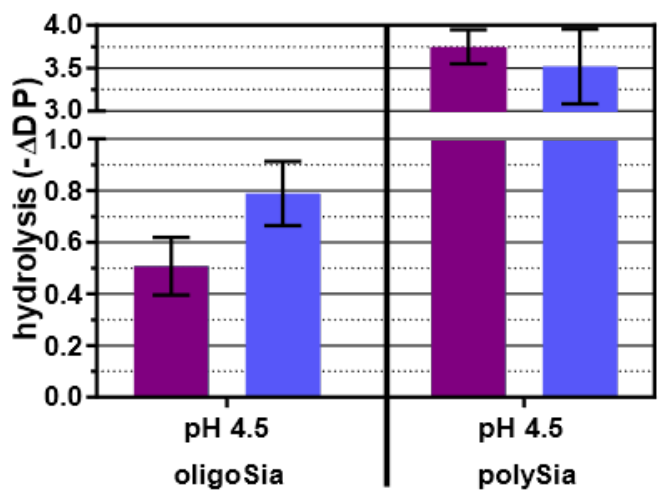

E) NEU3



enzyme-free control

\section{B) siaAU}

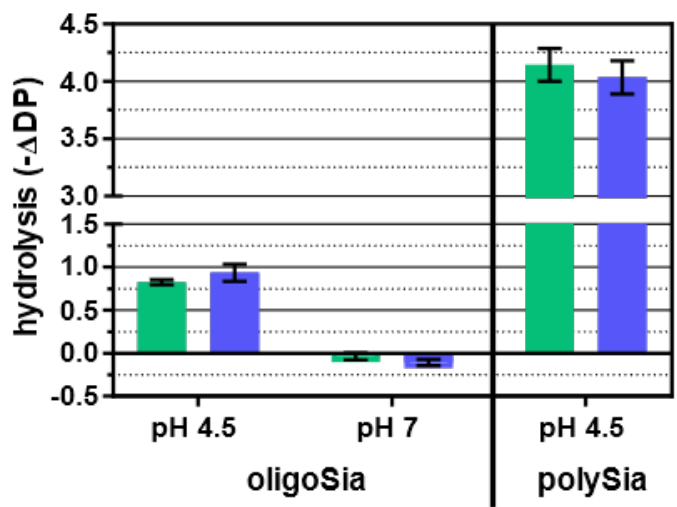

D) NEU2

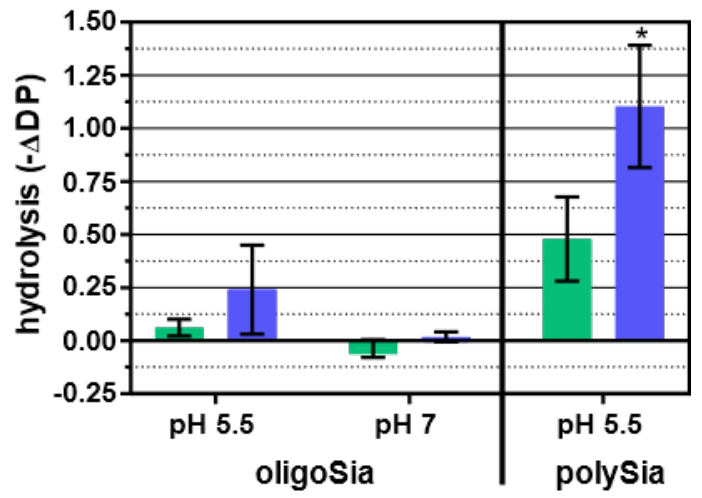

F) NEU4

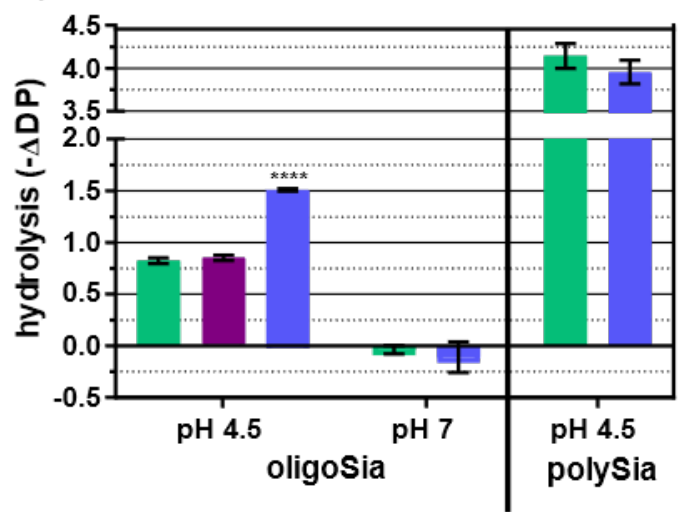

selective inhibitor control

NEU

Figure 3: Neuraminidase-catalyzed degradation assays. Enzyme activity was normalized

to $1 \mathrm{mU}$ enzyme activity apart from Endo-N, for which enzyme activity could not be normalized and so was used at $65 \mu \mathrm{g} / \mathrm{mL}$, and NEU1 which was normalized to $0.5 \mathrm{mU}$.

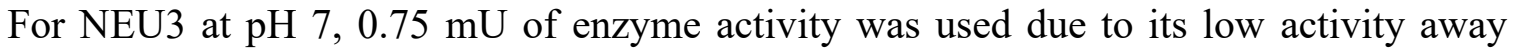


from the enzyme optimum $\mathrm{pH}$. Unpaired t-tests with Welch's correction were performed comparing the enzymatic conditions to their respective $\mathrm{pH}$ controls, where $*=\mathrm{p}<0.05$ and $* * * *=\mathrm{p}<0.0001$

We proceeded to test hNEU activity on polySia (DP 10-20) (Figure 3). Our results showed that, with the exception the Endo-N positive control, none of the neuraminidases tested had appreciable activity on polySia. Among these, NEU2 was the only isoenzyme to show increased hydrolysis compared to the $\mathrm{pH} 5.5$ control $(\mathrm{p}<0.05)$. NEU3 showed a small decrease in hydrolysis $(\mathrm{p}<0.05)$. Taken together, we ascribe these small differences in activity to variability in the assay rather than authentic differences in enzyme activity. Previous reports found that NEU2 did not cleave colominic acid, ${ }^{65}$ and we conclude that all four hNEU isoenzymes have minimal or no activity towards polySia.

Inhibition of oligoSia degradation by selective hNEU inhibitors.

Our group and others have developed isoenzyme-specific inhibitors of hNEU. ${ }^{67-71}$ Inhibitors of $\mathrm{NEU} 3^{68}$ and $\mathrm{NEU} 4^{69}$ can block glycolipid processing in vitro. To confirm that oligoSia degradation under hNEU treatment conditions was a result of neuraminidase activity, we used a NEU4 selective inhibitor (Figure 4, CY16600) to block enzymatic hydrolysis of oligoSia. ${ }^{69}$ Addition of the inhibitor to the assay mixture at $1.6 \mu \mathrm{M}(10 \mathrm{x}$ the $\left.\mathrm{IC}_{50}\right)^{69}$ gave a $\Delta \mathrm{DP}$ identical to the $\mathrm{pH}$ control (Figure 3F), indicating that NEU4catalyzed hydrolysis of oligoSia was completely blocked by the NEU4-selective inhibitor. Our NEU1 enzyme is produced by overexpression in HEK293 cells, and should not contain other NEU isoenzyme activity. ${ }^{11}$ Due to the sensitivity of oligoSia/polySia to small changes in $\mathrm{pH}$ and salt concentration (vide infra) we could not use the enzyme-free 
conditions as controls for NEU1. Thus, we used a selective NEU1 inhibitor, CG33300, ${ }^{67}$ (10x the $\mathrm{IC}_{50}$, Figure 3C) to confirmed that the differences observed could be attributed to NEU1 enzyme activity on oligoSia. As with the other isoenzymes, we did not observe NEU1 activity towards polySia compared to control.
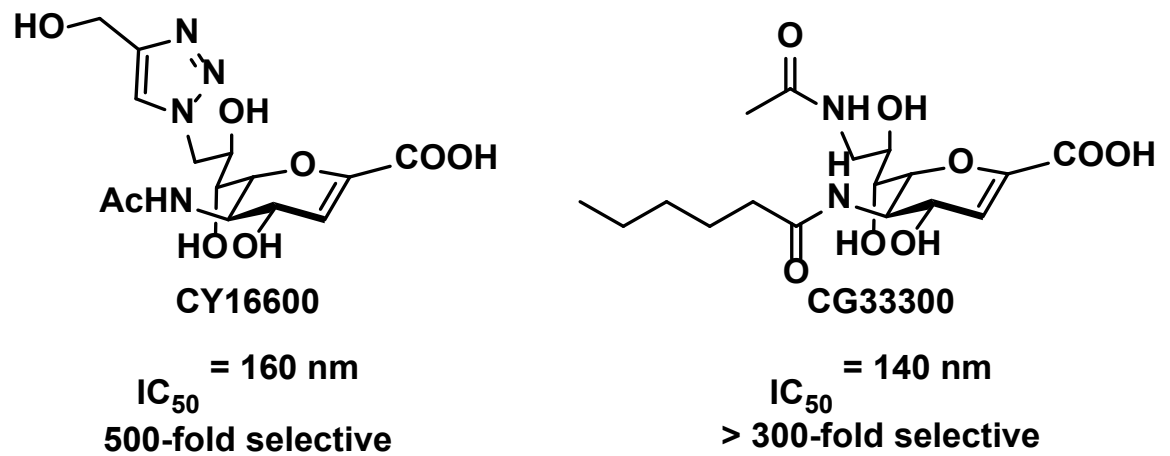

Figure 4: Structures of selective hNEU inhibitors. NEU4 inhibitor CY16600 is 500-fold selective for NEU4 and NEU1 inhibitor CG33300 is 300-fold selective for NEU1.

\section{Influence of salt concentration on oligoSia degradation.}

Our systematic investigation of hNEU activity on oligoSia/polySia provides evidence that hNEU may only cleave short polymers of sialic acid and only at acidic $\mathrm{pH}$. We hypothesize that these results could be explained through charge repulsion of polySia substrate to hNEU, or by different conformations of the substrates. These two factors are difficult to isolate experimentally. ${ }^{44,60}$ To test whether the relative ionic strength of the polymer influenced its accessibility to hNEU, we monitored oligoSia hydrolysis over a range of salt concentrations $(260 \mathrm{mM}$ to $80 \mathrm{mM}$; Figure 5). Increased buffer salt concentration had a small protective effect against hNEU-independent hydrolysis. ${ }^{41}$ Varying the buffer salt concentration did not change the $\Delta \mathrm{DP}$ for EndoN treatment. 
Conversely, decreasing the salt concentration correlated with a decrease in NEU4catalyzed hydrolysis of oligoSia. These data are consistent with charge screening of polysialic acid, ${ }^{39}$ and suggest that the relative ionic strength of oligoSia/polySia may influence the association kinetics of the polymer to the enzyme. We note that the $\alpha(2 \rightarrow 8)$ SiaT, ST8SiaIII, has a large electropositive groove to accommodate its polyanionic substrate not found in other SiaTs. ${ }^{72}$ These experiments do not exclude a role for conformational differences between oligoSia and polySia in hNEU catalysis.

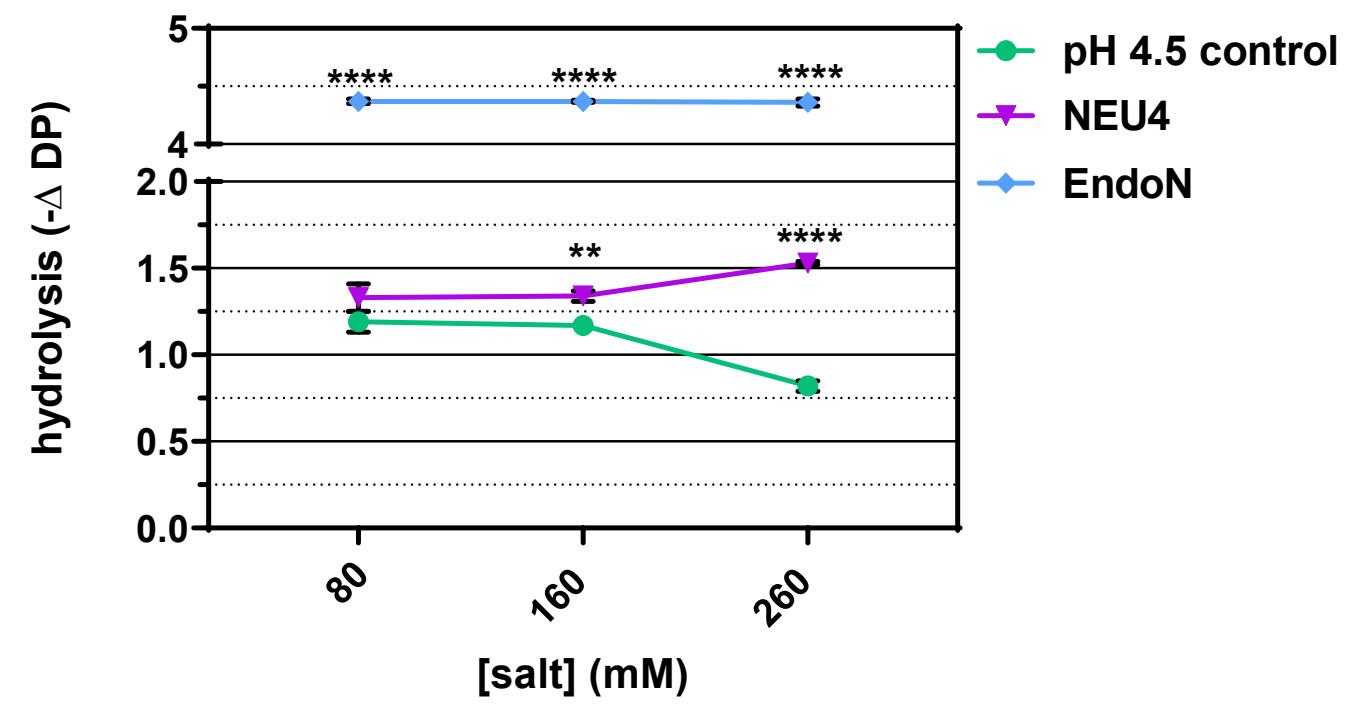

Figure 5: Effect of buffer salt concentrations on oligosia hydrolysis. Each point represents a mean of triplicate experiments with error bars denoting one standard deviation. Enzyme activity was normalized to $1 \mathrm{mU}$ with the exception of Endo-N, which was used at $65 \mu \mathrm{g} / \mathrm{mL}$. Unpaired t-tests with Welch's correction were performed comparing the enzymatic conditions to the $\mathrm{pH}$ control at each buffer concentration, where $* *=\mathrm{p}<0.01$ and $* * * *=\mathrm{p}<0.0001$. 


\section{The ongoing challenge of studying polySia.}

The sensitivity of our degradation assays to different salt concentrations highlights the challenge of studying polysialic acid. The unique chemistry of polySia makes it a challenging target. Factors which complicate the study of polysialic acid include sample consistency (DP), $\mathrm{pH}$, salt concentration, and method of detection. This challenge becomes apparent when reviewing the literature for examples of neuraminidase activity on polySia substrates. The siaAU enzyme is reported to cleave $\alpha(2 \rightarrow 3,6,8,9)$ linkages $^{45,64}$ and has been used to degrade polySia to smaller DP. Enzyme activity has been measured using a thiobarbituric acid assay, requiring strong acid and boiling. ${ }^{45}, 73$ Many reports using siaAU employed high concentration of enzyme or were performed at acidic $\mathrm{pH} .{ }^{14}$, 42, $74-76$ In this context, our observation that siaAU did not cleave oligoSia/polySia indicates that much, if not all, of reported activity may be attributed to acid-catalyzed hydrolysis.

Previous reports have identified NEU1, NEU2, and NEU4 isoenzymes as having activity on polysialic acid substrates. Murine NEU2 and NEU4 exhibited similar activity towards oligoSia while NEU1 was approximately twice as active. ${ }^{75}$ Conversely, a study of murine sialidases determined that only NEU4 cleaved oligoSia (DP $2-6$ ) using the thiobarbituric acid assay. ${ }^{46}$ Antibodies to polySia supported that NEU4b could cleave polysialic acid in vitro and in cellulo; however, we note that the antibodies used (12E3 and $12 \mathrm{~F} 8$ ) recognize epitopes of DP $>5$ and an undefined epitope, respectively. ${ }^{48}$ Murine NEU4b-catalyzed removal of polySia from NCAM in vitro is reported at near-neutral $\mathrm{pH} .{ }^{46}$ Thus, there is some disagreement in the literature on the specific NEU isoenzymes 
that hydrolyze polysialylated glycoproteins. Candidates also include murine NEU4a (polysialylated NCAM) $^{52}$ and human NEU1. ${ }^{13,53}$

\section{CONCLUSIONS}

This work suggests that degradation of polysialic acid substrates, especially larger polymers (DP > 8), may be largely independent of neuraminidase-catalyzed hydrolysis. In vitro studies showing enzyme-free polysialic acid hydrolysis under mild acidic conditions also found in biological systems has already prompted speculation that enzyme-free hydrolysis of polySia may occur in acidic environments of endosomes and lysosomes. ${ }^{41,77,78}$ Desialylation of polysialylated NCAM was found to be dependent on endocytosis. ${ }^{79}$ More recently, an antibody specific for polysialic acid (DP $>3$ ) was internalized by cells and co-localized with endosomal and lysosomal markers. ${ }^{80}$ Further investigation of polySia trafficking and degradation, as well as follow-up studies of hNEU isoenzyme activity on polySia, will be essential to confirming mechanisms of polySia regulation. Our assay design has enabled us to directly compare several factors that influence polySia degradation kinetics, including substrate $\mathrm{DP}, \mathrm{pH}$, and relative ionic strength of the media. Our results suggest that hNEU can only hydrolyze polymers of sialic acid with low DP at acidic $\mathrm{pH}$. 


\title{
METHODS
}

\author{
General methods.
}

All reagents were purchased from commercial sources and used without further purification unless otherwise noted. HPLC was performed with a Waters Delta 600 pump, and a Waters 600 controller with Empower 2 software. Eluted peaks were detected with a Waters 2996 photodiode array (PDA) detector (Waters Ltd.). Neuraminidase from A. ureafaciens was purchased from Millipore Sigma. Endo-N was a generous gift from Dr. Lisa Willis. Human neuraminidase enzymes NEU2-NEU4 were expressed as fusion proteins with maltose binding protein and were purified as described. ${ }^{4}, 81,82$ Human neuraminidase enzyme NEU1 was produced from HEK293E cells and was used as a crude cell lysate. ${ }^{11}$ Specific activity of the exosialidase enzymes was determined in comparison to a standard curve of neuraminidase from Clostridium perfringens (NanI) against 4-methylumbelliferyl $\quad \alpha$-D- $N$-acetylneuraminic acid (4MU-NANA). Neuraminidase activity was normalized to $1 \mathrm{mU}$, with exceptions. Our NEU1 expression system has lower activity ${ }^{11}$ than the other isoenzymes, and $0.5 \mathrm{mU}$ NEU1 was used at $\mathrm{pH}$ 4.5. At $\mathrm{pH} 7$, NEU1 had no detectable activity and NEU3 had reduced activity, so was used at $0.75 \mathrm{mU}$. Endo-N could not be normalized using the exosialidase assay so was used at $65 \mu \mathrm{g} / \mathrm{mL}$.

Oligo- and polysialic acid sample preparation.

Colominic acid (average MW $30000 \mathrm{kDa}, 45 \mathrm{mg}$ ) was dissolved in $4.5 \mathrm{~mL}$ of $0.25 \mathrm{M}$ $\beta$-mercaptoethanol, $9 \mathrm{mM} \mathrm{Na} \mathrm{S}_{2} \mathrm{O}_{4}$, and $20 \mathrm{mM}$ trifluoroacetic acid. The 1,2phenylenediamine $\left(8 \mathrm{mg}, 0.07 \mathrm{~mol}\right.$ ) was added and the mixture was heated at $50{ }^{\circ} \mathrm{C}$ for 2 
hrs. $\mathrm{NH}_{4} \mathrm{OH}(10 \mu \mathrm{L}$ of $28 \%)$ was added and the mixture was incubated at $37{ }^{\circ} \mathrm{C}$ for $2 \mathrm{~h} .{ }^{55}$, 57

Labelled polysialic acid was separated on a DNA Pac PA-100 anion exchange column $(9 \times 250 \mathrm{~mm})$ with a gradient of $2 \mathrm{M} \mathrm{NH}_{4} \mathrm{OAc}(\mathrm{pH} 8)$ in water $(3 \mathrm{~mL} / \mathrm{min}$ flow rate: $0 \%, 0 \%, 20 \%, 25 \%, 32.5 \%, 100 \%, 100 \%$, at $0,5,20,35,45,48,55$ minutes, respectively. $)^{46,47}$ Peaks were detected at $350 \mathrm{~nm}$. Fractions were collected and pooled to obtain oligosialic acid (DP 3-8) and polysialic acid (DP 10-20). For oligosialic acid, solvent was removed under vacuum and the remaining salt was removed by repeated washes through a centrifugal filter unit (3 $\mathrm{kDa} \mathrm{MWCO})$ before lyophilization. For polysialic acid, solvent was concentrated under vacuum and salt was removed by dialysis (3 $\mathrm{kDa} \mathrm{MWCO})$ followed by repeated washes through a centrifugal filter unit (3kDa MWCO) before lyophilization.

Oligo- and polysialic acid hydrolysis assays.

Assay buffer $(20 \mu \mathrm{L})$ was added to aliquots of oligo- or polysialic acid $(0.1 \mathrm{mg}$ of oligo- or $0.8 \mathrm{mg}$ of poly-). Unless otherwise stated, the assay buffer was $0.3 \mathrm{M}$ sodium acetate HEPES at $\mathrm{pH} 4.5,5.5$, or 7 . For controls, $20 \mu \mathrm{L}$ of neuraminidase buffer $(0.2 \mathrm{M}$ $\mathrm{NaCl}, 20 \mathrm{mM}$ MOPS, $10 \mathrm{mM}$ maltose and 10\% glycerol, $\mathrm{pH}$ 7.2) was added, and for enzymatic assays $20 \mu \mathrm{L}$ of $1 \mathrm{mU}$ of enzyme in neuraminidase buffer was added (for NEU1, $0.5 \mathrm{mU}$ of enzyme in 1X RIPA buffer was used). Mixtures were incubated at 37 ${ }^{\circ} \mathrm{C}$ for $5 \mathrm{~h}$. Ethanol $(10 \mu \mathrm{L})$ and $\mathrm{NH}_{4} \mathrm{OAc}(30 \mu \mathrm{L}, 0.2 \mathrm{M}, \mathrm{pH}$, with $1 \mathrm{mM}$ benzoic acid $)$ were added. The mixture was washed through a centrifugal filter unit $(30 \mathrm{kDa} \mathrm{MWCO}$ at $14000 \mathrm{rpm}$ for $30 \mathrm{~min}$ ) and the filtrate was analyzed after separation on a DNA Pac PA100 anion exchange column (4 x $150 \mathrm{~mm})$, monitored at $350 \mathrm{~nm}$. The gradient was $2 \mathrm{M}$ 
$\mathrm{NH}_{4} \mathrm{OAc}(\mathrm{pH} 8)$ in water $2 \mathrm{~mL} / \mathrm{min}: 0 \%, 0 \%, 20 \%, 25 \%, 100 \%, 100 \%$, at $0,5,20,35$, 38,43 minutes, respectively (oligosia) or: $0 \%, 0 \%, 20 \%, 25 \%, 32.5 \%, 100 \%, 100 \%$, at 0 , $5,20,35,45,48,55$ minutes, respectively (polysia).

For inhibitor assays NEU1 or NEU4 was incubated with their respective inhibitors for $10 \mathrm{~min}$ at room temperature prior to addition to oligosialic acid. Final concentrations of each inhibitor was $10 x$ the reported $\mathrm{IC}_{50}$ values. For the NEU1 inhibitor (C5-hexanamido-C9-acetamido-DANA, CG33300) the concentration was $1.4 \mu \mathrm{M},{ }^{67}$ and for the NEU4 inhibitor (9-[4-hydroxymethyl-[1,2,3]triazol-1-yl]-2,3-didehydro- $N$ acetylneuraminic acid, C9-4HMT-DANA, CY16600) the concentration was $1.6 \mu \mathrm{M} .{ }^{69}$ 


\section{ACKNOWLEDGEMENTS}

The authors wish to thank Dr. Lisa Willis (University of Alberta) for providing EndoN, Dr. Tianlin Guo for providing neuraminidase inhibitors, and Hanh-Thuc Ton Tran for samples of NEU1. CH acknowledges support from an NSERC CGSD Scholarship. This work was supported by a grant from the Natural Sciences and Engineering Research Council of Canada (NSERC) and the Alberta Glycomics Centre.

\section{SUPPORTING INFORMATION}

The Supporting Information is available free of charge on the ACS Publications website at DOI: 


\section{REFERENCES}

1. Miyagi, T., and Yamaguchi, K. (2012) Mammalian sialidases: physiological and pathological roles in cellular functions, Glycobiology 22, 880-896.

2. Monti, E., and Miyagi, T. (2012) Structure and function of mammalian sialidases, In SialoGlyco Chemistry and Biology I, pp 183-208, Springer.

3. Cairo, C. W. (2014) Inhibitors of the human neuraminidase enzymes, MedChemComm $5,1067-1074$.

4. Sandbhor, M. S., Soya, N., Albohy, A., Zheng, R. B., Cartmell, J., Bundle, D. R., Klassen, J. S., and Cairo, C. W. (2011) Substrate recognition of the membraneassociated sialidase NEU3 requires a hydrophobic aglycone, Biochemistry 50, 6753-6762.

5. Khedri, Z., Muthana, M. M., Li, Y., Muthana, S. M., Yu, H., Cao, H., and Chen, X. (2012) Probe sialidase substrate specificity using chemoenzymatically synthesized sialosides containing C9-modified sialic acid, Chemical Communications 48, 3357-3359.

6. Zamora, C. Y., d'Alarcao, M., and Kumar, K. (2013) Fluorogenic sialic acid glycosides for quantification of sialidase activity upon unnatural substrates, Bioorganic \& medicinal chemistry letters 23, 3406-3410.

7. Khedri, Z., Xiao, A., Yu, H., Landig, C. S., Li, W., Diaz, S., Wasik, B. R., Parrish, C. R., Wang, L.-P., and Varki, A. (2016) A chemical biology solution to problems with studying biologically important but unstable 9-O-acetyl sialic acids, $A C S$ Chemical Biology 12, 214-224.

8. Varki, A. (1992) Diversity in the sialic acids, Glycobiology 2, 25-40.

9. Varki, N. M., and Varki, A. (2007) Diversity in cell surface sialic acid presentations: implications for biology and disease, Laboratory investigation 87, 851 .

10. Smutova, V., Albohy, A., Pan, X., Korchagina, E., Miyagi, T., Bovin, N., Cairo, C. W., and Pshezhetsky, A. V. (2014) Structural Basis for Substrate Specificity of Mammalian Neuraminidases, PLoS ONE 9, e106320.

11. Hunter, C. D., Khanna, N., Richards, M. R., Rezaei Darestani, R., Zou, C., Klassen, J. S., and Cairo, C. W. (2018) Human neuraminidase isoenzymes show variable activities for 9-O-acetyl-sialoside substrates, ACS Chemical Biology 13, 922-932.

12. Hunter, C. D., Porter, E. M., and Cairo, C. W. (2020) Human neuraminidases have reduced activity towards modified sialic acids on glycoproteins, Carbohydrate Research 497, 108139.

13. Sumida, M., Hane, M., Yabe, U., Shimoda, Y., Pearce, O. M., Kiso, M., Miyagi, T., Sawada, M., Varki, A., and Kitajima, K. (2015) Rapid trimming of cell surface polysialic acid (PolySia) by exovesicular sialidase triggers release of preexisting surface neurotrophin, Journal of Biological Chemistry 290, 13202-13214.

14. Galuska, S. P., Geyer, R., Gerardy-Schahn, R., Mühlenhoff, M., and Geyer, H. (2008) Enzyme-dependent variations in the polysialylation of the neural cell adhesion molecule (NCAM) in vivo, Journal of Biological Chemistry 283, 17-28.

15. Galuska, S. P., Rollenhagen, M., Kaup, M., Eggers, K., Oltmann-Norden, I., Schiff, M., Hartmann, M., Weinhold, B., Hildebrandt, H., and Geyer, R. (2010) Synaptic cell adhesion molecule SynCAM 1 is a target for polysialylation in postnatal 
mouse brain, Proceedings of the National Academy of Sciences 107, 1025010255.

16. Curreli, S., Arany, Z., Gerardy-Schahn, R., Mann, D., and Stamatos, N. M. (2007) Polysialylated neuropilin-2 is expressed on the surface of human dendritic cells and modulates dendritic cell-T lymphocyte interactions, Journal of Biological Chemistry 282, 30346-30356.

17. Werneburg, S., Buettner, F. F., Erben, L., Mathews, M., Neumann, H., Mühlenhoff, M., and Hildebrandt, H. (2016) Polysialylation and lipopolysaccharide-induced shedding of E-selectin ligand-1 and neuropilin-2 by microglia and THP-1 macrophages, Glia 64, 1314-1330.

18. Yabe, U., Sato, C., Matsuda, T., and Kitajima, K. (2003) Polysialic acid in human milk CD36 is a new member of mammalian polysialic acid-containing glycoprotein, Journal of Biological Chemistry 278, 13875-13880.

19. Zuber, C., Lackie, P. M., Catterall, W., and Roth, J. (1992) Polysialic acid is associated with sodium channels and the neural cell adhesion molecule N-CAM in adult rat brain, Journal of Biological Chemistry 267, 9965-9971.

20. Mühlenhoff, M., Manegold, A., Windfuhr, M., Gotza, B., and Gerardy-Schahn, R. (2001) The impact of N-glycosylation on the functions of polysialyltransferases, Journal of Biological Chemistry 276, 34066-34073.

21. Rutishauser, U. (1998) Polysialic acid at the cell surface: biophysics in service of cell interactions and tissue plasticity, Journal of cellular biochemistry 70, 304-312.

22. Johnson, C. P., Fujimoto, I., Rutishauser, U., and Leckband, D. E. (2005) Direct evidence that neural cell adhesion molecule (NCAM) polysialylation increases intermembrane repulsion and abrogates adhesion, Journal of Biological Chemistry 280, 137-145.

23. Kanato, Y., Kitajima, K., and Sato, C. (2008) Direct binding of polysialic acid to a brain-derived neurotrophic factor depends on the degree of polymerization, Glycobiology 18, 1044-1053.

24. Ono, S., Hane, M., Kitajima, K., and Sato, C. (2012) Novel regulation of fibroblast growth factor 2 (FGF2)-mediated cell growth by polysialic acid, Journal of Biological Chemistry 287, 3710-3722.

25. Villanueva-Cabello, T. M., Gutiérrez-Valenzuela, L. D., López-Guerrero, D. V., Cruz-Muñoz, M. E., Mora-Montes, H. M., and Martínez-Duncker, I. (2019) Polysialic acid is expressed in human naïve CD4+ $\mathrm{T}$ cells and is involved in modulating activation, Glycobiology 29, 557-564.

26. Drake, P. M., Stock, C. M., Nathan, J. K., Gip, P., Golden, K. P., Weinhold, B., Gerardy-Schahn, R., and Bertozzi, C. R. (2009) Polysialic acid governs T-cell development by regulating progenitor access to the thymus, Proceedings of the National Academy of Sciences 106, 11995-12000.

27. Stamatos, N. M., Zhang, L., Jokilammi, A., Finne, J., Chen, W. H., El-Maarouf, A., Cross, A. S., and Hankey, K. G. (2014) Changes in polysialic acid expression on myeloid cells during differentiation and recruitment to sites of inflammation: role in phagocytosis, Glycobiology 24, 864-879.

28. Tajik, A., Phillips, K. L., Nitz, M., and Willis, L. M. (2020) A new ELISA assay demonstrates sex differences in the concentration of serum polysialic acid, Analytical Biochemistry 600, 113743. 
29. Suzuki, M., Suzuki, M., Nakayama, J., Suzuki, A., Angata, K., Chen, S., Sakai, K., Hagihara, K., Yamaguchi, Y., and Fukuda, M. (2005) Polysialic acid facilitates tumor invasion by glioma cells, Glycobiology 15, 887-894.

30. Elkashef, S. M., Allison, S. J., Sadiq, M., Basheer, H. A., Morais, G. R., Loadman, P. M., Pors, K., and Falconer, R. A. (2016) Polysialic acid sustains cancer cell survival and migratory capacity in a hypoxic environment, Scientific Reports 6, 33026.

31. Wang, X., Li, X., Zeng, Y.-N., He, F., Yang, X.-M., and Guan, F. (2016) Enhanced expression of polysialic acid correlates with malignant phenotype in breast cancer cell lines and clinical tissue samples, International journal of molecular medicine 37, 197-206.

32. Miyahara, R., Tanaka, F., Nakagawa, T., Matsuoka, K., Isii, K., and Wada, H. (2001) Expression of neural cell adhesion molecules (polysialylated form of neural cell adhesion molecule and L1-cell adhesion molecule) on resected small cell lung cancer specimens: In relation to proliferation state, Journal of surgical oncology 77, 49-54.

33. Rutishauser, U. (2008) Polysialic acid in the plasticity of the developing and adult vertebrate nervous system, Nature Reviews Neuroscience 9, 26.

34. Sato, C., and Hane, M. (2018) Mental disorders and an acidic glycan-from the perspective of polysialic acid (PSA/polySia) and the synthesizing enzyme, ST8SIA2, Glycoconjugate journal 35, 353-373.

35. Varea, E., Guirado, R., Gilabert-Juan, J., Martí, U., Castillo-Gomez, E., BlascoIbáñez, J. M., Crespo, C., and Nacher, J. (2012) Expression of PSA-NCAM and synaptic proteins in the amygdala of psychiatric disorder patients, Journal of psychiatric research 46, 189-197.

36. Barbeau, D., Liang, J. J., Robitalille, Y., Quirion, R., and Srivastava, L. K. (1995) Decreased expression of the embryonic form of the neural cell adhesion molecule in schizophrenic brains, Proceedings of the National Academy of Sciences 92, 2785-2789.

37. Abe, C., Yi, Y., Hane, M., Kitajima, K., and Sato, C. (2019) Acute stress-induced change in polysialic acid levels mediated by sialidase in mouse brain, Scientific Reports 9, 9950.

38. Yang, P., Yin, X., and Rutishauser, U. (1992) Intercellular space is affected by the polysialic acid content of NCAM, The Journal of cell biology 116, 1487-1496.

39. Yang, P., Major, D., and Rutishauser, U. (1994) Role of charge and hydration in effects of polysialic acid on molecular interactions on and between cell membranes, Journal of Biological Chemistry 269, 23039-23044.

40. Katchalsky, A., and Spitnik, P. (1947) Potentiometric titrations of polymethacrylic acid, Journal of Polymer Science 2, 432-446.

41. Manzi, A. E., Higa, H. H., Diaz, S., and Varki, A. (1994) Intramolecular self-cleavage of polysialic acid, Journal of Biological Chemistry 269, 23617-23624.

42. Zhang, Y., and Lee, Y. C. (1999) Acid-catalyzed lactonization of $\alpha 2$, 8-linked oligo/polysialic acids studied by high performance anion-exchange chromatography, Journal of Biological Chemistry 274, 6183-6189. 
43. Lifely, M. R., Gilbert, A. S., and Moreno, C. (1981) Sialic acid polysaccharide antigens of Neisseria meningitidis and Escherichia coli: esterification between adjacent residues, Carbohydrate Research 94, 193-203.

44. Baumann, H., Brisson, J. R., Michon, F., Pon, R., and Jennings, H. J. (1993) Comparison of the conformation of the epitope of. alpha.(2. fwdarw. 8) polysialic acid with its reduced and $\mathrm{N}$-acyl derivatives, Biochemistry 32, 4007-4013.

45. Uchida, Y., Tsukada, Y., and Sugimori, T. (1979) Enzymatic properties of neuraminidases from Arthrobacter ureafaciens, The Journal of Biochemistry 86, 1573-1585.

46. Takahashi, K., Mitoma, J., Hosono, M., Shiozaki, K., Sato, C., Yamaguchi, K., Kitajima, K., Higashi, H., Nitta, K., Shima, H., and Miyagi, T. (2012) Sialidase NEU4 hydrolyzes polysialic acids of neural cell adhesion molecules and negatively regulates neurite formation by hippocampal neurons, Journal of Biological Chemistry 287, 14816-14826.

47. Nakata, D., and Troy, F. A. (2005) Degree of Polymerization (DP) of Polysialic Acid (PolySia) on Neural Cell Adhesion Molecules (N-CAMs) Development and application of a new strategy to accurately determine the DP of polysia chains on N-CAMs, Journal of Biological Chemistry 280, 38305-38316.

48. Sato, C., and Kitajima, K. (2013) Disialic, oligosialic and polysialic acids: distribution, functions and related disease, The Journal of Biochemistry 154, 115136.

49. Aalto, J., Pelkonen, S., Kalimo, H., and Finne, J. (2001) Mutant bacteriophage with non-catalytic endosialidase binds to both bacterial and eukaryotic polysialic acid and can be used as probe for its detection, Glycoconjugate Journal 18, 751-758.

50. Jokilammi, A., Korja, M., Jakobsson, E., and Finne, J. (2007) Generation of lectins from enzymes: Use of inactive endosialidase for polysialic acid detection, In Lectins, pp 385-395, Elsevier.

51. Jakobsson, E., Schwarzer, D., Jokilammi, A., and Finne, J. (2012) Endosialidases: versatile tools for the study of polysialic acid, In SialoGlyco Chemistry and Biology II, pp 29-73, Springer.

52. Shiozaki, K., Koseki, K., Yamaguchi, K., Shiozaki, M., Narimatsu, H., and Miyagi, T. (2009) Developmental change of sialidase neu4 expression in murine brain and its involvement in the regulation of neuronal cell differentiation, Journal of Biological Chemistry 284, 21157-21164.

53. Demina, E. P., Pierre, W. C., Nguyen, A. L., Londono, I., Reiz, B., Zou, C., Chakraberty, R., Cairo, C. W., Pshezhetsky, A. V., and Lodygensky, G. A. (2018) Persistent reduction in sialylation of cerebral glycoproteins following postnatal inflammatory exposure, Journal of Neuroinflammation 15, 10.1186/s1297412018-11367-12972.

54. Sajo, M., Sugiyama, H., Yamamoto, H., Tanii, T., Matsuki, N., Ikegaya, Y., and Koyama, R. (2016) Neuraminidase-dependent degradation of polysialic acid is required for the lamination of newly generated neurons, PloS one 11, e0146398.

55. Hara, S., Takemori, Y., Yamaguchi, M., Nakamura, M., and Ohkura, Y. (1987) Fluorometric high-performance liquid chromatography of N-acetyl-and Nglycolylneuraminic acids and its application to their microdetermination in human 
and animal sera, glycoproteins, and glycolipids, Analytical Biochemistry 164, 138-145.

56. Hara, S., Yamaguchi, M., Takemori, Y., Nakamura, M., and Ohkura, Y. (1986) Highly sensitive determination of $\mathrm{N}$-acetyl-and $\mathrm{N}$-glycolylneuraminic acids in human serum and urine and rat serum by reversed-phase liquid chromatography with fluorescence detection, Journal of Chromatography B: Biomedical Sciences and Applications 377, 111-119.

57. Inoue, S., Lin, S.-L., Lee, Y. C., and Inoue, Y. (2001) An ultrasensitive chemical method for polysialic acid analysis, Glycobiology 11, 759-767.

58. Wang, L., Wang, D., Zhou, X., Wu, L., and Sun, X.-L. (2014) Systematic investigation of quinoxaline derivatization of sialic acids and their quantitation applicability using high performance liquid chromatography, RSC Advances 4, 45797-45803.

59. Anumula, K. R. (1995) Rapid quantitative determination of sialic acids in glycoproteins by high-performance liquid chromatography with a sensitive fluorescence detection, Analytical Biochemistry 230, 24-30.

60. Evans, S., Sigurskjold, B., Jennings, H., Brisson, J.-R., To, R., Altman, E., Frosch, M., Weisgerber, C., and Kratzin, H. (1995) Evidence for the extended helical nature of polysaccharide epitopes. The 2.8. ANG. resolution structure and thermodynamics of ligand binding of an antigen binding fragment specific for. alpha.-(2. fwdarw. 8)-poly (sialic acid), Biochemistry 34, 6737-6744.

61. Brisson, J. R., Baumann, H., Imberty, A., Perez, S., and Jennings, H. J. (1992) Helical epitope of the group B meningococcal. alpha.(2-8)-linked sialic acid polysaccharide, Biochemistry 31, 4996-5004.

62. Kitazume, S., Kitajima, K., Inoue, S., and Inoue, Y. (1992) Detection, isolation, and characterization of oligo/poly (sialic acid) and oligo/poly (deaminoneuraminic acid) units in glycoconjugates, Analytical Biochemistry 202, 25-34.

63. Morley, T. J., Willis, L. M., Whitfield, C., Wakarchuk, W. W., and Withers, S. G. (2009) A new sialidase mechanism bacteriophage $\mathrm{K} 1 \mathrm{~F}$ endo-sialidase is an inverting glycosidase, Journal of Biological Chemistry 284, 17404-17410.

64. Chu, K. C., Ren, C. T., Lu, C. P., Hsu, C. H., Sun, T. H., Han, J. L., Pal, B., Chao, T. A., Lin, Y. F., and Wu, S. H. (2011) Efficient and stereoselective synthesis of $\alpha$ $(2 \rightarrow 9)$ oligosialic acids: from monomers to dodecamers, Angewandte Chemie International Edition 50, 9391-9395.

65. Tringali, C., Papini, N., Fusi, P., Croci, G., Borsani, G., Preti, A., Tortora, P., Tettamanti, G., Venerando, B., and Monti, E. (2004) Properties of Recombinant Human Cytosolic Sialidase HsNEU2: The enzyme hydrolyzes monomerically dispersed GM1 ganglioside molecules J. Biol. Chem. 279, 3169-3179.

66. Li, W., Xiao, A., Li, Y., Yu, H., and Chen, X. (2017) Chemoenzymatic synthesis of Neu5Ac9NAc-containing $\alpha 2-3$-and $\alpha 2-6$-linked sialosides and their use for sialidase substrate specificity studies, Carbohydrate Research 451, 51-58.

67. Guo, T., Héon-Roberts, R., Zou, C., Zheng, R., Pshezhetsky, A. V., and Cairo, C. W. (2018) Selective inhibitors of human neuraminidase 1 (NEU1), Journal of Medicinal Chemistry 61, 11261-11279. 
68. Guo, T., Dätwyler, P., Demina, E., Richards, M. R., Ge, P., Zou, C., Zheng, R., Fougerat, A., Pshezhetsky, A. V., and Ernst, B. (2018) Selective inhibitors of human neuraminidase 3, Journal of Medicinal Chemistry 61, 1990-2008.

69. Albohy, A., Zhang, Y., Smutova, V., Pshezhetsky, A. V., and Cairo, C. W. (2013) Identification of selective nanomolar inhibitors of the human neuraminidase, NEU4, ACS Medicinal Chemistry Letters 4, 532-537.

70. Li, Y., Cao, H., Yu, H., Chen, Y., Lau, K., Qu, J., Thon, V., Sugiarto, G., and Chen, X. (2011) Identifying selective inhibitors against the human cytosolic sialidase NEU2 by substrate specificity studies, Mol. BioSyst. 7, 1060-1072.

71. Magesh, S., Moriya, S., Suzuki, T., Miyagi, T., Ishida, H., and Kiso, M. (2008) Design, synthesis, and biological evaluation of human sialidase inhibitors. Part 1: Selective inhibitors of lysosomal sialidase (NEU1), Bioorg. Med. Chem. Lett. 18, 532-537.

72. Volkers, G., Worrall, L. J., Kwan, D. H., Yu, C.-C., Baumann, L., Lameignere, E., Wasney, G. A., Scott, N. E., Wakarchuk, W., and Foster, L. J. (2015) Structure of human ST8SiaIII sialyltransferase provides insight into cell-surface polysialylation, Nature structural \& molecular biology 22, 627-635.

73. Uchida, Y., Tsukada, Y., and Sugimori, T. (1977) Distribution of neuraminidase in Arthrobacter and its purification by affinity chromatography, The Journal of Biochemistry 82, 1425-1433.

74. Janas, T., Nowotarski, K., and Janas, T. (2011) The effect of long-chain bases on polysialic acid-mediated membrane interactions, Biochimica et Biophysica Acta (BBA)-Biomembranes 1808, 2322-2326.

75. Davies, L. R., Pearce, O. M., Tessier, M. B., Assar, S., Smutova, V., Pajunen, M., Sumida, M., Sato, C., Kitajima, K., and Finne, J. (2012) Metabolism of Vertebrate Amino Sugars with N-Glycolyl Groups: Resistance of $\alpha 2-8$-linked Nglycolylneuraminic acid to enzymatic cleavage, Journal of Biological Chemistry 287, 28917-28931.

76. Kakehi, K., Hirose, A., Tamai, T., Taga, A., and Honda, S. (1996) Analysis of Nacetylneuraminic acid oligomers by high-performance capillary electrophoresis, Analytical Sciences 12, 171-176.

77. Kiss, J. Z., and Rougon, G. (1997) Cell biology of polysialic acid, Current Opinion in Neurobiology 7, 640-646.

78. Schnaar, R. L., Gerardy-Schahn, R., and Hildebrandt, H. (2014) Sialic acids in the brain: gangliosides and polysialic acid in nervous system development, stability, disease, and regeneration, Physiological reviews 94, 461-518.

79. Monzo, H. J., Park, T. I., Dieriks, B. V., Jansson, D., Faull, R. L., Dragunow, M., and Curtis, M. A. (2013) Insulin and IGF 1 modulate turnover of polysialylated neural cell adhesion molecule (PSA-NCAM) in a process involving specific extracellular matrix components, Journal of neurochemistry 126, 758-770.

80. Cox, E. C., Thornlow, D. N., Jones, M. A., Fuller, J. L., Merritt, J. H., Paszek, M. J., Alabi, C. A., and DeLisa, M. P. (2019) Antibody-mediated endocytosis of polysialic acid enables intracellular delivery and cytotoxicity of a glycan-directed antibody-drug conjugate, Cancer Research 79, 1810-1821.

81. Albohy, A., Li, M. D., Zheng, R. B., Zou, C., and Cairo, C. W. (2010) Insight into substrate recognition and catalysis by the human neuraminidase 3 (NEU3) 
through molecular modeling and site-directed mutagenesis, Glycobiology 20, 1127-1138.

82. Zhang, Y., Albohy, A., Zou, Y., Smutova, V., Pshezhetsky, A. V., and Cairo, C. W. (2013) Identification of selective inhibitors for human neuraminidase isoenzymes using C4, C7-modified 2-deoxy-2, 3-didehydro-N-acetylneuraminic acid (DANA) analogues, J. Med. Chem. 56, 2948-2958. 